Book Review

\title{
Obliquity: Why Our Goals are Best Achieved Indirectly
}

\author{
Author: John Kay \\ Reviewed by: Shiva Kumar Srinivasan \\ IIPM Chennai, India \\ sksrinivasan2008@hotmail.com
}

What is obliquity? Why does it matter in management theory? In addition, why are goals, as John Kay puts it, 'best achieved indirectly?' These then are the main questions that are addressed in this book. However, to begin at the beginning, a note on the origins of the book: this book began as an article that appeared in the Financial Times in January 2007 but was subsequently expanded into a full-length book. Kay's interest in this topic is related to his work as a business academic, economist, and as a newspaper columnist. He is also a renowned institutional builder who is associated with the Institute for Fiscal Studies, the London Business School, the London School of Economics, St. John's College and the Said Business School at the University of Oxford. Kay's variegated career, which has helped him to not only pursue the life of the mind but also continually test the applications of theoretical knowledge in areas like economics, finance, and strategy, is the source of his interest in the notion of obliquity. He has also served as a management consultant for a number of years in addition to the achievements and affiliations listed above. This book begins with the intuition that problem solving is not what we often think it to be - i.e. it is often not susceptible to a simple linear approach. However, at the same time, it is not clear if anybody has actually been able to come to terms with the indirect approach in totality. What appears to work on most occasions are, quite simply, forms of theoretical opportunism (that pragmatists like Stanley Fish and Richard Rorty are obsessed with) rather than a specific set of cognitive protocols that can be formalized to the satisfaction of both theorists and practitioners. This is all the more important to appreciate since Kay understood during his stint as a consultant that clients do not always follow the advice given to them by consultants, or even bother to deploy the decision-making models that are painstakingly developed in the consultancy business. Kay is therefore tempted to ask a simple question: why not?

It is in the attempt to answer why it is so difficult to get buy-in from clients for the solutions proposed by consultants that prompts Kay to argue that what we probably need is an indirect approach to diagnosing and solving problems. Kay starts with a number of interesting epigraphs to suggest a strategic direction for his book encompassing a range of thinkers including Adam Smith. But the line that summarizes his approach most effectively is the relationship between the articulation of truth and the challenges of problem solving in the work of the American poet Emily Dickinson ('the belle of Amherst') who writes 'tell all the truth, but tell it slant.' The reason: 'success in circuit lies'. Obliquity then is an attempt to take Dickinson's advice forward to increase the attention spans of the client and stakeholders for whatever truth emerges in a given situation analysis albeit with the safeguard of indirectness so that those who are affected by the solution have the time to both think-through and work-through the solution. While what Kay is doing is interesting, it has been attempted before by Jon Elster, a Cambridge political scientist, who argued that a number of important affective states are mainly 'by-products' and not directly achievable through human efforts at problem solving. Alternatively, to put it simply, humans can experience certain affective states only indirectly since our minds have to be tricked into experiencing these affects or emotions. Kay's wager then is that a similar approach to the identification of problems and the articulation of the solution will be an important form of value addition to the theory and practice of management. The first two parts attempt to make an effective case for being able to identify obliquity in the environment in the forms of complexity that confront us. The third and final part is an attempt to understand the difficulties involved in solving problems directly. The main source of this complexity (apart from the multiplication of variables) is the ongoing discussion about whether or not human nature or behavior is rational. Opinions swing wildly amongst the students of the decision sciences and behavioral economics because the attempt to create models of decision-making must be clear as to what their main theoretical presuppositions are. 
An analogue to Kay's approach might be to say that the knowing subject must trick himself into positing and accepting solutions because the unconscious is a source of systematic disruption in his own cognitive patterns; and, furthermore, as both game theorists and psychoanalytic theorists like John Forrester are fond of pointing out, mediated by inter-subjective dynamics. The indirect approach probably works best because it gets 'buy-in' more effectively not only from the point of view of the client, but most importantly from the locus of the consultant himself since in the Freudian model of cognition the consultant is both the subject and the object of the knowledge that is proffered for consumption in the form of a solution. There is a kind of 'uncertainty principle' at work in terms of the cognitive patterns that constitute our attempts to know the world; hence, we must trick ourselves into accepting certain truths indirectly since direct articulation will generate resistance. This is a problem that psychoanalysts confront all the time in the analytic situation where they are haunted, as Freud puts it, by the difference between the analyst's knowledge of the patient's neurosis and the patient's knowledge of his own neurosis. What are therapeutic - if at all - are not the analyst's knowledge, but the patient's knowledge and ability to interpret his symptom along with the intellectual and emotional capacity to work-through a trauma effectively in the Freudian clinic. This gap between the analyst's knowledge and the patient's knowledge cannot be overcome directly since the patient needs to be able to trick his own mind into accepting the truths that emerge lest he disrupt his own progress on the linear path of finding a cure. This is the structural gap that haunted Kay when he understood that the client was not willing to use the decision-making models that he would recommend as a consultant. What is even more interesting is Kay's admission that he himself was not willing to deploy the decision-making models that he was will not to recommend to clients. Resistance, to put it simply, in a Freudian idiom, cuts both ways; it emerges in the context of the transference and the counter-transference since both the analyst and the patient are subject to the affective turbulence that underpins the dynamics of the transference when it emerges as a fundamental resistance to the analytic process.

Kay's book can then be understood as an attempt to translate insights of this sort though not necessarily from a psychoanalytic source to the domains of strategy, policy, and behavioral economics. The source of cognitive distortion for Kay emerges from the 'Franklin's Gambit', which is a term that symbolizes the mind's propensity to rationalize decisions that have been taken unconsciously or semi-consciously but rationalized subsequently through a decision-making model. Furthermore, it is not clear as to what if anything constitutes rationality if human behavior can be 'predictably irrational'. The range of cognitive possibilities along the rational-irrational cognitive spectrum then is precisely what is at stake in getting into a meaningful set of presuppositions in behavioral economics on the traditional set of relations between belief, thought, reason, and human action. It is the inability to work out how these processes interact in relation to a theory of rationality that has delayed the project of the European Enlightenment that Immanuel Kant envisaged as a historical possibility in $18^{\text {th }}$ century Europe, and which Christopher Norris, the Cardiff-based philosopher, argues must be reinstituted as the ethical object of contemporary critical theory, critical management studies, and critical legal studies These then are the residual theoretical concerns that emerge in any attempt at building a theory; these concerns emerge again and again albeit in the dominant discourse of any given era. It is time then to think through, as Kay does, these problems in the context of both theoretical and applied forms of economics as manifest, say, in strategic approaches to human action be it in the context of business policy or public policy.

This book includes a number of examples from the personal and professional domains where the articulation and achievement of strategic goals remains elusive on the linear front. While the reader may not necessarily appreciate the significance of each of these examples or disagree with Kay's interpretation of some, what is at stake is not a particular example with which reasonable individuals can disagree or agree to disagree but to partake of the larger spirit of Kay's endeavor, which is to capture the notion of obliquity as a pervasive but hitherto unrecognized factor in decision making. While obliquity has been recognized in specific domains as evidenced by Kay's examples that is not the same as developing a general theory of obliquity, which is what the goal of this book is. Has Kay himself used an indirect approach to theorizing obliquity like he advices us to do so in the subtitle of this book? The jury, I am afraid, is still out on that question since it will pose an important theoretical challenge to Kay's effort in this direction. What is the relationship between selfreflexivity in theoretical endeavors such as this and a theory of obliquity? That, needless to say, might well be the topic of Kay's sequel to this splendid attempt to bring alive the joys of behavioral economics as a foundation for decision making in strategic contexts. This book will be of use to anybody who is interested in 
the theory and practice of decision making, especially in contexts where the decision-maker must come to terms with the unconscious promptings of his own desire. A linear notion of decision-making will work in simple contexts but not necessarily in complex situations. The notion of obliquity will make it possible to understand when to approach decision making directly and when to approach it indirectly. While this sort of advice can be given by any theorist who is well informed of the psychological and psychoanalytic aspects of decision-making, understanding John Kay's institutional achievements will make it possible for readers to situate him as both an academic theorist and as a practitioner of decision-making. 